\title{
Priorities, identity and the environment: Negotiating the early teenage years
}

\begin{tabular}{|r|l|}
\hline Journal: & The Journal of Environmental Education \\
\hline Manuscript ID & 02-16-127.R3 \\
\hline Manuscript Type: & Original Research \\
\hline Theoretical Perspective: & Constructivism/Interpretivism \\
\hline Methodology: & Narrative Inquiry \\
\hline Discipline: & Education \\
\hline Education Areas of Expertise: & Primary/Elementary, Secondary / High School \\
\hline Data Collection \& Analysis & Interviews \\
Methods: & \\
\hline & \\
\hline
\end{tabular}


Table 1 Generic questions arising from each theoretical perspective, and aligned with the research questions

\begin{tabular}{|c|c|c|}
\hline Research Question & $\begin{array}{l}\text { Theoretical } \\
\text { perspective }\end{array}$ & Generic Question \\
\hline \multirow{2}{*}{$\begin{array}{l}\text { What school-mediated } \\
\text { and extra-school } \\
\text { environmental } \\
\text { experiences do school } \\
\text { students perceive in } \\
\text { retrospect as significant } \\
\text { in their lives? }\end{array}$} & $\begin{array}{l}\text { Significant Life } \\
\text { Experiences }\end{array}$ & $\begin{array}{l}\text { Have there been experiences in my personal life, or my } \\
\text { schooling, which have influenced my thinking/feeling/acting } \\
\text { with respect to the environment? }\end{array}$ \\
\hline & $\begin{array}{l}\text { Transformative } \\
\text { Learning }\end{array}$ & $\begin{array}{l}\text { Have I learnt things in my personal life, or through my } \\
\text { schooling, which have caused me to change my } \\
\text { thinking/feeling/acting with respect to the environment? }\end{array}$ \\
\hline \multirow{4}{*}{$\begin{array}{l}\text { What are the students' } \\
\text { current thinking and } \\
\text { perceptions about how } \\
\text { they, and other people, } \\
\text { are acting as sustainable } \\
\text { citizens? }\end{array}$} & $\begin{array}{l}\text { Environmental } \\
\text { literacy }\end{array}$ & $\begin{array}{l}\text { What do I understand about my relationship to the } \\
\text { environment? }\end{array}$ \\
\hline & Values & $\begin{array}{l}\text { What kind of person do I want to be with regard to the } \\
\text { environment? }\end{array}$ \\
\hline & Action Competence & What actions am I taking for the environment, and why? \\
\hline & $\begin{array}{l}\text { Environmental } \\
\text { Identity }\end{array}$ & How do I see myself in relation to the environment? \\
\hline
\end{tabular}




\title{
Priorities, identity and the environment: Negotiating the early teenage years
}

\author{
Chris Eames ${ }^{1}$, Miles Barker ${ }^{1}$ and Carol Scarff ${ }^{2}$ \\ ${ }^{1}$ University of Waikato, Hamilton, New Zealand ${ }^{2}$ University of British Columbia, Kelowna, Canada
}

\begin{abstract}
This study focuses on the negotiation of environmental identity by ten New Zealand students as they progressed from late primary school to junior secondary school. Interviews with these students and their parents focussed on six theoretical perspective prominent in environmental education: significant life experiences, transformative learning, environmental literacy, values, action competence and environmental identity. Thirteen major themes emerged, which are discussed in terms of two overarching findings. Firstly, the deep-seated, composite and pivotal resonances between home and school influences in effective environmental education for sustainability (EEfS) learning are described, and suggestions are made for how this can be better taken into account. Secondly, a focus on the complex negotiation of the early teenage years suggests how promoting EEfS might occur more productively in secondary schools.
\end{abstract}

Keywords: environmental identity, teenagers, secondary school, significant life experiences

\section{Introduction}

How and why do some people initially become 'green', and how and why do some stay green? Documenting the origins of individuals' environmentally sustainable thinking, attitudes and actions (here we employ 'green-ness' in line with the colloquial emphasis in New Zealand, for example, see Manawatu Standard (2013)), and plotting these 'green' life-trajectories, rightly occupies a significant place in the literature of environmental education (see for example, Chawla, 1999 and Payne, 2000). Although there is an understandable and regrettable dearth of substantial longitudinal studies, accounts exist of the identity development of teenagers from studying environmental science (Blatt, 2014), of retrospective reflections of now-'green' younger adults (for example, Almers, 2013) and more mature adults (for example, Barker, 2012) are available.

In the study reported here, we focus on what is often seen as a key time in a person's life: the move from childhood primary schooling (approx. six to 12 years of age) to the adolescent early teenage years (13 to 15 years of age). We examine the shifting priorities and evolving sense of identity with regard to the environment with children, who have been identified by their primary school teachers as having already enthusiastically and knowledgeably embraced environmental principles and practices from a young age, as they enter their adolescent years. As we three authors have had long-standing contact with the well-intentioned efforts of schools, we have inevitably focussed on the relative contributions of school-mediated and extra-school environmental experiences in this timeframe. 


\section{The Context of the Study}

That childhood (that is, years six to twelve) environmental experiences are frequently pivotal has been widely acknowledged (see for example, AguirreBielschowsky, Freeman, \& Vass, 2012; Hart, 2003; Hutchison, 1998). Reviewing studies of research into the formative experiences of environmental activists and educators, Chawla and Cushing (2007, p. 440) claim that, "in these studies, from half to more than $80 \%$ of the respondents identify childhood experiences of nature as a significant experience, such as free play, hiking, camping, fishing and berry picking. They mention influential family members or other role models equally often or second in importance." Hutchinson (1998), in his book Growing Up Green, concluded that "children's plasticity of response to change, aptitude for wonder, natural inquisitiveness, need to frame an initial relationship to the world" uniquely position them to "play an integral role in changing the course of human and Earth history." (p. 152)

Among New Zealand children, an evident nurturing ground for this childhood potential to be 'green' - and the source of the interviewees in this study - has been the Enviroschools Programme. Although Environmental Education (the forerunner in New Zealand to EEfS) has been (Keown, 2002), and remains (Eames and Barker, 2011), a low educational priority in New Zealand, the Enviroschools Programme has constituted a beacon of success. Initiated in 1993, this substantive national school-based initiative now operates in over 900 schools, although most are smaller (less than 500 students) primary schools (Enviroschools, 2016; Williams, 2012). Enviroschools promotes a whole school approach (Wilson-Hill, 2003; Eames, Barker, Wilson-Hill, \& Law, 2010) that sees a school as part of a sustainable community. While similar percentages $(20-25 \%)$ of primary, middle and secondary schools are enrolled as enviroschools, Williams (2012) contrasts the more in-depth and holistic nature of the programmes in primary and middle schools with the programmes in secondary schools that are often "struggling, ad hoc and fragmented." (p. 39)

This study focuses on the experiences of ten children who had, in the opinion of their teachers, participated deeply in New Zealand primary school EEfS programmes in well-established enviroschools. As nine and ten-year-olds, they had manifested the kind of 'green' readiness that theorists such as Hutchinson, Hart and others claim is a unique property of that age group. We were then interested in whether that nascent green identity had persisted or been subverted through their teenage years.

\section{Towards a framework: Six theoretical perspectives}

To facilitate our inquiry, we were mindful that "it is crucial what paradigm is taken as the point of departure" (Almers, 2013, p. 117). Almers contrasts the 'moralistic' (or 'behaviour modification') paradigm with the more open-ended and critical-thinking-based 'educational' paradigm. So in considering the conversations we proposed to hold with young people, we felt a need to set up as open-ended and wide-ranging a dialogue as we could, exclusively privileging no single tradition. In not working within the consensus of any one tradition - in fact, in spanning various areas and theoretical frameworks - we consciously opted for "a reflexive and inventive scholarship mode" rather than "a gap-spotting mode" of research (Alvesson and Sandberg, 2013, p. 109). While eschewing a quest for a 
single grand theoretical synthesis, we selected from the major traditions which had underpinned our own professional lives over the last five years, those of our immediate colleagues (especially in Canada, New Zealand and Australia), and those evident at a range of recent international symposia and conferences.

To this end, we surveyed six such theoretical perspectives, our purpose being to inquire into how the orientation of each of these might enable us both to formalise our research questions and to construct research instruments that would enable us to explore deeply the developing 'greenness' of these young people. As our focus was on this process of 'becoming and staying green', this necessitated considering an eclectic mix of perspectives that cross science and social science boundaries, including elements of citizenship, psychology and theories of change. We hoped that by using such a diversity of lenses we would illuminate a more holistic insight into our question. We were conscious of the relationships between these perspectives (e.g. the inclusion of values in environmental literacy, the role of significant life experiences in action competence) and expected that these overlaps may provide a rich picture of development.

What follows now is a brief account of each of the six perspectives. Space limits our ability here to present a detailed literature review, including describing the nuanced debates within each perspective; rather, we aim to highlight elements within each that permitted us to explore their contribution to our research task. We conclude with an emergent generic question or questions that epitomise(s) how that particular theoretical perspective informed our data gathering.

\section{1) Significant Life Experiences}

This theoretical perspective was initiated in the USA with Tanner's (1980) study of "citizens who have demonstrated amply their informed and responsible activism" (p. 20). Typically in this tradition, the subjects have been adult members of singleinterest groups, and the research has been phenomenographical, i.e. it describes people's own self-understanding of the sources of their commitment to environmental action and the meaning that these experiences hold for them. Significant life experiences, then, are those meaningful formative influences (Chawla, 1999), that in this study are framed by connections to the environment.

How persuasive are school experiences? Adding a quantitative dimension has enabled Chawla (1999) to report on the relative importance of school experiences as a source of commitment to environmental protection. For the people in Kentucky and in Norway (mainly aged between 30 and 49 years) whom she interviewed, she found that education ranked below experiences of natural areas, family, organizations and negative experiences, but above friends, vocation, sense of social justice, book or author, principles or religion and concern for children/grandchildren. Swedish (Wickenberg \& Almers, 2008) and American (Arnold, Cohen \& Warner, 2009) studies of the life experiences of environmentally-committed youth similarly suggest that schools contribute an important but only partial element in 'becoming green' (in our study's terms).

An explanation as to why formal education is ranked as only a moderate influence might be found in the work of Chawla and Cushing (2007). They broadened the notion of significant life experiences by synthesizing studies of antecedents for 
action (i.e. 'entry-level variables) with studies of antecedents of political action, and studies of the development of personal and collective competence. This metasynthesis suggested that environmental education typically addresses only private sphere environmentalism and "often fail(s) to engage students in a strategic analysis of the most effective way to address problems" (p. 448). Chawla and Cushing comment that "defending young people's right to navigate these processes is equivalent to defending the role of schools to prepare students for authentic democratic citizenship" (ibid).

In overview, this theoretical perspective privileges such a generic question as:

Have there been experiences in my personal life, or my schooling, which have influenced my thinking/feeling/acting with respect to the environment?

\section{2) Transformative Learning}

Transformative learning can be thought of as 'creative re-visioning.' It changes who we are by changing our ability to participate, to belong, and to negotiate meaning (Sterling, 2001). It is transformative learning that is a necessary, but not sufficient, condition for durability of change, which in terms of this study in examining young people's thinking and feeling towards environmental and sustainability issues may have lead to changes in action.

The literature on transformative (or transformational) learning generally addresses two distinct contexts: personal, and school-mediated transformations. Personal transformational learning, at least for adults "aims at evoking a new consciousness and understanding, and promotes the human experience by thinking, selfexpression and actions" (Hudson, 1999, p. 246). Bennetts (2003), who interviewed nearly 200 adults in South West England about major changes in their thinking, feeling, acting and being, found that "significant transformations fell into categories of self-transformation, coping with and instigating change in self and others, transformed relationships, increased educational drive, career improvement and better quality of life" (p. 457). In this personal transformative sense, 'becoming green' is driven by the knowledge that change is possible, necessary and rewarding. Personal transformations and the evolution of a self-identity can therefore be seen as largely synonymous.

For young people, any account of 'becoming green' can also be expected to be coloured to a large extent, by how transformative was one's schooling - how far it reflected some of the principles of sustainability education itself: participation, responsiveness, process awareness, problem negotiation, and being democratically grounded.

In overview, this theoretical perspective privileges such a generic question as: Have I learnt things in my personal life, or through my schooling, which have caused me to change my thinking/feeling/acting with respect to the environment?

\section{3) Environmental literacy}

This theoretical perspective focuses on literacy with respect to the environment (Roth, 1992), framed as knowing, caring and practical competence (Orr, 1992). 
More recently, it has been defined as the "knowledge of environmental concepts and issues; the attitudinal dispositions, motivation, cognitive abilities, and skills, and the confidence and appropriate behaviors to apply such knowledge in order to make effective decisions in a range of environmental contexts" (Hollweg et al, 2011, p. 59).

It implies an understanding of the Earth and the principle that ecosystems have evolved to sustain the web of life, attended by an understanding of the interdependence between natural processes and human ways of living. But it further implies an emotional connection and a willingness to act (Chawla, 1999).

In overview, this theoretical perspective privileges such generic questions as:

What do I understand about my relationship to the environment?

4) Values

Callenbach (2005, p. 46-47) claims that "most environmental debates ultimately involve value conflicts." It follows, as Ohman (2008, p.110) contends, that "how we prepare coming generations to deal with value-laden differences and make agreements, compromises and changes" is one of the major challenges facing EEfS.

Nevertheless, in New Zealand schools, teachers have traditionally been given little encouragement to challenge students on the "quasi-psychological and spiritual" level (Barker, 2008, p.12). Instead, at least until recently, values education in New Zealand has tended to suffer from a "relative lack of experience and development" (Keown, 2000, p. 2). As in other countries, it often takes the shape of "character education' (Lawley, 2002) and it has focused more on virtues to be acquired by individual students, rather than exploring and problematising one's own values and beliefs and exploring and negotiating values with others.

An explicit connection between values and 'becoming green' is evident in The New Zealand Curriculum (Ministry of Education, 2007), which makes it clear that consideration is important in all teaching and learning. This curriculum specifies "ecological sustainability, which includes care for the environment", as one of eight aspects that "students should be encouraged to value" (p.10).

It is clear that values or attitudes can influence behavior and hence impact on both our being (Fromm, 1976) and our doing. However, several recent studies with teenagers have shown that having environmental values, however, does not always translate into environmentally-friendly behavior (Kasapoğlu \& Turan, 2008), although it can be a predictor of intentions to act (Fielding \& Head, 2012; Prabawa-Sear \& Baudains, 2011).

In overview, this theoretical perspective privileges such generic questions as: What kind of person do I want to be with regard to the environment?

What kind of world do I want to live in?

\section{5) Action Competence}

Action competence was conceptualised (Jensen \& Schnack, 1997) as action taken in relation to the environment, and as an ideal to work towards, rather than a goal 
(Mogensen \& Schnack, 2010). It demands engagement in authentic experiences that encourage learners to ask critical questions about the how, why, where and who (Jensen, 2002), to help them to make decisions about change and what actions could enable this change, and therefore connects with both significant life experiences and transformative learning, as described above.

A student who exhibits action competence would demonstrate conscious awareness, strong commitment, critical reflection and democratically-responsible actions for the environment. As Mogensen and Schnack (2010) note, not only are the actions committed and intentional, "the intentions, motives and reasons all have an intrinsic relation to the actions. It will be a different action if the intention turns out to be different" (p. 61). In this study, such a notion allowed us to probe the actions students might take and their motivations for doing so, such that their descriptions of actions taken might provide insight into their understanding of their relationship to, and their values towards, the environment (hence connecting to environmental literacy and values as described above). The emphasis of action competence on student agency, the student's belief in their own ability to take action for the environment, and to do so in democratic and participatory ways that counter the possible determinism (Wals, Geerling-Eijff, Hubeek, van der Kroon, \& Vader, 2008) of some educational approaches, were also important to consider in this perspective.

This theoretical perspective privileges such generic questions as:

What actions am I taking for the environment, and why?

\section{6) Environmental Identity}

According to Wenger (1998), identity is important because it helps individuals "come to realise who they are and what really matters to them by helping sort out what to pay attention to, what to participate in, and what to stay away from" (p. 6). Indeed, the notion of 'green-ness' is a colloquial and pervasive, if imprecise, way of talking about the crucial matter of one's very environmental identity - although that relationship itself is much debated. The concept of environmental identity connects with one's views of environmental issues and one's role and potential in them. The notion of environmental identity has the potential to move beyond conceptualizations of attitudes by emphasising how senses of self are constructed through multiple contexts, including the classroom (Hayes-Conroy and Vanderbeck, 2005, p. 312). Ecological ideas are not enough, and identity emphasises more the development of an ecological self (Naess, 1989) with a sense of relationship to natural and social ecosystems (Thomashow, 1995). This has been eloquently argued by Sauvé (2010), in considering how we might 'be in the world' in relation to ourselves, to others and to the environment.

There is recognition that issues of identity are important for understanding why students adopt particular perspectives and choose certain courses of action in relation to the environment (Thomashow, 1995; Stets and Biga, 2003). To begin to develop a sense of oneself as 'green', that is, someone who feels responsible for and committed to environmental concerns, entails asking oneself thoughtprovoking questions such as: What do I know about the place where I live? Where do things come from? How do I connect to the Earth? What is my purpose as a human being? 
Environmental identity has been examined in depth in recent studies of teenagers and two positions appear to be at odds with each other. The crux of the concern appears to be the degree to which the social element is involved. One conception of the term is represented in the work of Stapleton (2015) who critiques the idea that a connection to the natural environment is central to the development of environmental identity as useful but limiting. Stapleton draws on the work of Kempton and Holland (2003) who propose a 'social environmental identity' that places the social in the centre, rather than the natural world (Stapleton, 2015, p. 95). She argues that it is "through engagement with practice, action, and recognition that individuals are constantly in the process of becoming" (p. 96). She draws on Wenger (1998), who notes that there is a "deep connection between identity and practice" such that, "the experience of identity in practice is a way of being in the world" (p. 151), and that complicated interactions work synergistically to produce identity. Therefore, Stapleton (2015) argues that connection to the environment is, "only one aspect of several that should be examined within the theoretical construct of environmental identity" (p. 95).

A second position worthy of mention here is that of Blatt's (2014) research which explored students' environmental identities and how they were impacted by the content of an Environmental Science course. The focus was on students' identities as affirmed or disconfirmed during classroom activities, and the importance of "establishing personal connections with environmental issues" (Blatt, 2014, p. 194). In reference to Thomashow $(1995$, p. 3), Blatt argues that the work here is on ecological identity that "refers to all the different ways people construe themselves in relationship to the earth as manifested in personality, values, actions, and sense of self." Rather than being concerned with the social interactions involved in environmental identity, Blatt places the development of students' relationship with the environment and issues concerning the environment as her focal point.

In overview, this theoretical perspective privileges such a generic question as: How do I see myself in relation to the environment?

\section{The Methodological Framework}

Firstly, our survey of these six theoretical perspectives reveals that, through whichever lens becoming 'green' is viewed, the place of schooling in the process is always seen as a component. However, the relative importance of schoolmediated and extra-school environmental influences, and their subtle interactions, is problematic. This resonates with the wider literature: if schooling in EEfS is a major factor in becoming green, its current effectiveness has sometimes come in for caustic criticism (e.g. Van Matre, 1990); alternatively, others hold visionary faith in its possibilities (e.g. Hutchinson, 1998). In the light of these perceptions of schooling, and given our intentions for the study, we therefore framed two research questions (see Table 1).

Secondly, in seeking an interpretivist methodology, our analysis of the six theoretical perspectives also pointed the way towards setting up conversations with student and parent participants that would be suitably eclectic. 
Thirdly - and again towards setting up conversations with students and parents we aligned the six theoretical perspectives with the two Research Questions in a two/four split. Because the generic questions emerging from the 'significant life experiences' and 'transformative learning' theoretical perspectives (above) were couched in the past tense, we treated these as retrospective, i.e. aligning with Research Question 1 and pertaining to personal life history.

\section{Insert Table 1 about here}

Similarly, the generic questions to emerge from the 'environmental literacy', 'values', 'action competence' and 'environmental identity' theoretical perspectives (above) were couched in the present tense; these we aligned with Research Question 2 that addresses each participant's current environmental position.

\section{Methods}

This study involved interviews with ten students and with one or both of their parents. Two interview protocols were developed, one for use with each student, and one for simultaneous use with the student's parent(s). The construction of the protocols was an iterative process of discussions in meetings attended by us and by three teacher colleagues (see 'Acknowledgements') from primary schools where the student interviewees, yet to be selected, had attended.

The student interview protocol was designed to be semi-structured, and while it was intended that, where appropriate, responses would be obtained to all designated questions (tagged SQ1 - SQ36), there was plenty of scope for following emergent lines of inquiry. In a few cases, the questions were almost the same as the generic questions that had emerged from the descriptions of the theoretical perspectives, for example, SQ19: "Have you ever thought about what kind of world you want to live in?" (see Values theoretical perspective, above). Mostly, however, the generic questions were contextualised. For example, the generic question from the Action Competence theoretical perspective "What environmental capabilities do I possess?" generated SQ16: "Would you consider planting trees, recycling rubbish, writing to the newspaper, or going on a protest march? Why/Why not?" The 36 interview questions were sequenced in groups under the six theoretical perspectives, with the early part of the interview comprising retrospective questions feeding into Research Question 1, i.e. those questions generated from the Significant Life Experiences theoretical perspective (SQ1-5) and Transformative Learning theoretical perspective (SQ6-7). There was one proviso to this: to avoid the student assuming that because we were teachers, these initial seven questions related only to experiences in schools, we held back specific school-based questions until late in the interview under the heading 'School Experiences' (SQ24-32).

The parent interview protocol was compiled and structured similarly. Comprising 30 questions, its purpose was triangulation - to cross-check factual material with the student interview, and to probe how the student's and the parents' perceptions compared. 
The ten now secondary school student interviewees (four boys and six girls) were identified by their previous primary enviroschool school teachers as having, at that stage, enthusiastically and knowledgeably embraced environmental principles and practices from a young age and, especially, during their schooling years 5 and 6 (when they were aged nine and 10). For convenience, the sample was confined to students who had remained in the same city (one of New Zealand's larger) for their subsequent school education. At interview, seven were now aged 13 years (and were in Year 9), one was aged 14 years (in Year 10), and two were aged 15 years (also in Year 10). Three were attending an all-boys' school (pseudonyms Robert, Adrian, Craig), two were attending an all-girls' school (Emily, Hayley) and five were attending co-educational schools (one boy, James; four girls, Kerry, Lucy, Susan and Brooke). They were all European/pakeha New Zealanders, and we make no claim regarding the inclusivity of this study and therefore no claims regarding cultural transferability of our findings. It is also recognised that each of the participants came from families from a high socioeconomic group and this may have influenced their school and family experiences in relation to the environment. We acknowledge the critical importance of culture, and potentially socioeconomics, in relationships to the environment, and this is an area for further study which was beyond the scope of our work. In every case, one parent, or both parents together, consented - always very willingly - to be interviewed. Ethical approval was obtained for all the relevant processes and procedures.

The tape-recorded interviews were held in the evening in the family homes. The student interviews, each conducted by one of the authors, lasted between 45 and 75 minutes; at the same time, the parent interviews, each conducted by one of the three teacher colleagues (all of whom had been trained in educational research methods) and held in an adjacent room, each took about 45 minutes. The taperecordings of all 20 interviews were later transcribed in full and participantverified. Each author then conducted a preliminary analysis of the student and parent responses from an allocated section of the protocols, searching for emergent themes in the data. These themes were then presented at a second round of iterative meetings with the team of researchers and teacher colleagues, and this process continued until consensus had been reached on an evidence-based set of emergent themes.

\section{Findings}

The following presentation and analysis of data is organised according to the six theoretical perspectives allied to the research questions, as in Table 1. We conclude each of the six sections with the major themes to emerge.

\section{1) Significant Life Experiences}

By way of establishing rapport and creating biography, the conversations with both students and parents began with questions about recollections of the student's life experiences in outdoor/natural environment settings in their life to date, and their feelings about them. We were interested in both school-mediated and extraschool environmental experiences.

In overview, some of the most highly rated Significant Learning Experiences (SLEs) comprised those in natural or rural settings: outdoor adventures and play time during childhood often accompanied by a family member, teacher or friend; 
outdoor summer camps; activities with groups and organizations (e.g., Boy Scouts); and environmental projects at home and school.

Many accounts of SLEs focused on a significant person featured in the students' lives. Serving as mentors and role models, significant family members and friends had contributed a powerful environmental impact on these young persons. For example, Adrian shared vivid memories of experiences with family. He described how, "with my grandparents, we always do river walks. From here we can actually get to River Road so we've been all the way up the river in both directions." Such experiences impacted how the students saw the environment around them and increased their awareness, as evidenced by Adrian's parent who confirmed that "as a family we do walking ... go on family tramps or go round the lake. If we go around the lake the boys increasingly wanted to stop and take pictures of lilies or have a close look at something that they might see". James' parents had run a business teaching overseas university students about the New Zealand environment and he shared that "my parents ran a conservation studies course. [We were] travelling around finding natural stuff and looking at stuff ... [up to the age of five]. I learned alongside the university students [about] all the animals around there and plants". Brooke noted that "As a family we were always doing a reasonable amount of things in the outdoors, but we're not huge [hikers] ... but most holidays we'd go into some kind of outdoor setting in preference to going to the movies". These depictions of family members setting the stage for environmental experiences were threaded throughout the research data.

Environmental improvement projects, both at school and at home, also seemed important in the lives of these young people. Revitalising a naturally formed gully, part of the grounds of their primary school, was one such project for a number of these students. Cleaning out garbage and weeds, replanting native plants, and monitoring for the return of native insects and birds to the gully, were some of the smaller projects taken on. Brooke recounted how at her primary school "there was a gully and that was quite a big part of (our school) life, the gully, and that's definitely like a big outdoor sort of thing". For Emily, who also attended that school, this resonated with a similar project in a gully near her home, as she said, "at home we decided to plant out our own gully and so I was involved in that".

Indeed, depictions of students connecting environmental experiences at home and at school were common throughout the research data. Vegetable gardening is another example of such activity at school and in which Adrian spoke of being at home where "we've got the vege patches and recycling bins and a couple of fruit trees ... I help with that at home." Lucy's mother commented how from an early age Lucy liked helping in the garden at home and then got into gardening at school. Lucy spoke of her primary school where "I was in the Gardening Club and that was the first year and we were just in that year doing planning, because that was my last year at primary school".

All six students who had attended one of the two primary schools indicated that one project had made a substantial impact, even drawing in members of the students' families. The project was to build an eco-classroom, and it inspired and encouraged student-directed planning, design and implementation (Wake \& Eames, 2013). One of Craig's parents was involved and remembered this well: 
"[The children] did the planning, they worked out what the classroom design problem was, and how they were going to solve it, rather than being told." Craig explained this as "we were like the face of it, like when we needed concrete for the job I actually phoned up, and talked to them and arranged it. We presented, we researched, but it was mostly under the guidance of the teacher." In contrast, to this highly memorable experience, it was noticeable that only one of the 10 students mentioned any project or experiences at their present secondary schools as being significant to them.

In overview, emergent themes pertaining to the Significant Life Experiences theoretical perspective were as follows:

1. For all of these students, their primary school experiences and their home and family life (especially outdoor experiences) in their pre-secondary school years were both strong influences.

2. School projects that involved parents (e.g., building the eco-classroom), and the resonances with experiences that could be carried out in both the school and the home setting (e.g., gardening, gully restoration, and walks in the outdoors), were especially powerful.

\section{2) Transformative Learning}

Our conversations around this theoretical perspective began by asking questions about students' interest in, and possible change in attitude towards, the environment. Students were asked if any experiences led them to think or feel differently about the environment and whether or not they thought they had changed as a result of such experiences.

The primary school years appeared to have led to some transformative learning. Robert, who, describing himself, as one who "always (tries to) take the environment into account", spoke clearly of the difference primary school, especially years 5 and 6, had made for him: "Before [Primary School] I wouldn't have really cared very much but now I take environmental factors into consideration". One of Adrian's parents commented that "he [Adrian] just throws himself into things and something that has really been significant is the ecoclassroom, which came along and was another opportunity for him. It was probably a launch pad for him to get interested in environment things".

There was some evidence in the data that connected with the transformational learning stages espoused by Mezirow (2000). Becoming conscious of the impact of human activity at large was illuminating for Susan, who decried "To be honest if those people want to damage the world, you want to get a time machine and come back, like 3000 years later, see what that's done to the world and hopefully they change their behaviours". After taking part with her parents in a recent successful anti-mining protest march, Kerry said "at the moment with the mining, I've started to think a lot ... I was quite moved that everyone thought that [the environment] was worth marching for", indicating her recognition that one's discontent and the process of transformation are shared (Mezirow, 2000).

Generally, however, the method of gathering self-reports through interviewing did not elicit clear evidence of transformational learning, either school generated or home generated, in which the young people expressed conviction for change. 
In overview, emergent themes pertaining to the Transformative Learning theoretical perspective are as follows:

1. The evidence of transformational learning was not clear, possibly due to the nature of data gathering that did not permit in-depth examination of change.

2. There was some evidence of changes in thinking linked to both school and out of school experiences.

\section{3) Environmental literacy}

In this part of the conversation we examined the students' and parents' views in two aspects of environmental literacy: how important participants felt it was for people to think about environmental issues (and what local issues were important to think about), and their own understandings about the role of people in nature.

All ten students felt that it was important for people to think about environmental issues. Some students, like Kerry, allied this importance to the concept of sustainability: "Well, it's definitely important on a long-term basis. The whole thing about sustainability is being able to, like, live a good life without trashing everything you have". When asked about which local issues were important for people to think about, the students identified water quality (7/10), biodiversity loss $(4 / 10)$, transport (3/10) and climate change (2/10).

Interestingly, two students clearly felt that it was important for people to think in order to form opinions on issues, as Robert said,

I think getting people thinking is what, it makes them form their own opinions, and then they feel they're own attachment to it and then they will go on varying degrees to solve this problem to what they can, and they need to form their own opinions, they can't just be told what they need to do.

Adrian connected the importance of thinking to the development of knowledge, attitudes and actions towards the environment when he said, "if people aren't sort of thinking about the environmental issues ... then people aren't going to really know about it or be concerned about it and then nothing's going to happen". However, Susan noted some changes in priorities:

I think it is very important for people to think about it like that but at [secondary] school not many people do because they're, at the moment they're thinking on what type of jobs they're going to do, they've got big grades to get jobs that they want.

The students' parents also unanimously agreed that it was important for people to think about environmental issues, many professing this importance to be crucial, which was indicative of their own environmentally-friendly attitudes. When asked if they felt their child thought the same way as they did, half had no doubt they did, while the other half were more unsure of their child's position.

In considering the human relationship to nature, the students discussed ideas of equity, power and control. In terms of equity, James drew on the idea of interdependence when he claimed that alongside humans "there are lots of other 
animals and plants that play an equally vital role in the ecosystem". Kerry echoed this theme through evoking an idea of species equity: "We should sort of treat nature as we would treat us - just to make room for a house - if trees were humans you wouldn't go and cut down a whole lot of humans just to make room for you". Craig continued this theme and extended it to notions of power: "We are part of nature and it's very hard to control something that controls you, kind of. It's kind of like one of those things where you can't really - you shouldn't have that power because eventually somebody's going to get greedy and, well, misuse it".

In overview, emergent themes pertaining to the environmental literacy theoretical perspective are as follows:

1. The students professed to be unequivocal about environmental issues: despite the potential distractions, everyone needs to engage their thinking in, and to take responsibility for, environmental issues like water quality.

2. The students were adamant that the human/environment relationship should be characterised by notions of interdependence and equity rather than by ambitions to control nature.

\section{4) Values}

In this central section of the conversations with students and with parents we discussed values-drenched matters: what kind of world they would like to live in, the place of the natural environment in that world, and who might feel a sense of responsibility towards the natural environment.

When we asked the students about what kind of world they wanted to live in, the thrust of half of the students' responses was towards environmental values. They nominated a world where biodiversity is evident (James: "Lots of animals and plants"); or a world free of pollution (Lucy: "No rubbish, on the streets or whatever and just like tidier kind of cities all round"); or a world marked by sustainable resources (Adrian: "Everybody would live in sustainable houses that had solar panels and wind turbines and grow their own food"; and Craig: "A gradual shift from non-renewable resources to renewable resources and ecofriendly stuff'). However, even for these five students, social values were also clearly evident in their responses. For example, Adrian went on to allude to the value of human co-operation: "[where everyone] tried to help those who hadn't got food, and traded things, that sort of thing".

However, for the other five students, social values - and in particular, the value of human co-operation - comprised the major emphasis of their responses. For example, Robert said "If it was a perfect society and everything, but people aren't perfect, so it's just everyone does their part and are conscious towards other people". Brooke saw the overcoming of human conflict as a pre-requisite for achieving the co-operation necessary for the kind of world she wanted to live in, stating "I think if (violence) goes and people become more peaceful, then if they don't have to worry about fighting they'll be able to think more about the environment".

In fact, as we talked more deeply about the kind of world they would want to live in, three broad social-value-related frames emerged: 
1) Three interviewees only considered questions of social values in their entire initial responses, without specifically relating these values to their desired world. However, when prompted by a later question about the place of the natural environment in that world, they were readily able to explain how social values have the power to generate or subvert the natural components of their ideal world.

2) How a fundamental change in social values is needed, in order to achieve the kind of world they wanted to live in, was graphically indicated by two interviewees for whom the gloomy prospect of a salutary worldwide catastrophe was probably necessary before a change in human values could occur. For example, Craig contemplated "a world where half the northern hemisphere is covered in ice as featured in [the movie] The Day After Tomorrow".

3) When the students were asked, 'What could prevent this [desired world] from happening?', eight students focused on social values that were not environmentally-friendly, including: selfishness (Emily: "people who just don't give a damn ... that they're wrecking the environment"); exploitation (James: "people who would prefer to exploit ... deforestation and over-mining, overfishing"); undervaluing dialogue (Craig: "we're all separate nations"); and disrespectfulness (Kerry: “(lack of) respect for our land”).

Five students offered instances of responsibility in considering their personal actions. For example, Adrian said, "Well, I can do what I can do because I can make my own life not impact super greatly; like, I can not go on lots and lots of airplane flights and burn lots of fuel and I can live as sustainably as I possibly can". However, Lucy explicitly ruled out any sense of responsibility for other people, arguing that "I don't feel responsible for what other people are doing but I feel responsible for what I'm doing and what I should be doing".

When we asked them directly about who should be responsible apart from themselves, the answers were again somewhat equivocal. Tensions clearly exist in these young peoples' lives because of the gap between a value of 'everyone' contributing and their peers' levels of environmental commitment. Even among chosen close friends, these tensions seemed to exist. As Robert put it, "Yea, I have some friends and they're, one could sort of scale concerns from not at all (across to) completely, and everyone (else) somewhere in between". The zeal exhibited in the primary years appeared to have worn off, as Emily put it "A lot of my friends aren't as passionate now; also because we're teenagers and ... yeah".

Brooke was also very articulate about the conflicts that currently exist between the environmental values previously acquired in her earlier years and the cultural values that exist around teenage culture. This was exemplified by a decline in her desire to actually experience natural environments, as she noted "when I was younger I enjoyed it more. I would kind of go outside and do it anyway ... but most teenagers nowadays all sit inside and they'll text and they'll go on the computer and stuff, and they won't be able to think about what's outside". Initially, as a secondary school student, she could feel herself succumbing to this peer mentality: "Being a teenager, ignorance comes with the territory so I'm starting to not really care about (the natural world)". However, some kind of values tussle was still occurring for her: "but then when I'm by myself I think about it and think that's kind of selfish and I probably should take better care of stuff around me, and then when I go outside I really enjoy myself'. Brooke's father had no doubt that 
traces of her earlier values system were enduring, stating "You would never see her throw a piece of rubbish away, it's just not in her. I think she's got some behaviours that I think are probably lifelong behaviours".

Then there were those students who appeared to have undergone some sort of values change from being an environmentally active to a relatively passive individual. Several mentioned that as they grew into their teenage years, attending secondary school, that their enthusiasm for the environment waned to some extent. Technology, peer pressure and exams were named as some of the reasons. For example, Emily, when asked if her interest in the natural environment had changed over time, responded that "as I've gotten older, other things have become important as well, like boys and clothes and, you know, that kind of thing. But it's still something I'm passionate about, but when I was younger it was like my main thing, it was the only thing". Craig summed this up with patent honesty: "I've sort of grown out of it because, well, I can't be bothered going down there [in the gully] and getting all sweaty and muddy".

In overview, emergent themes pertaining to the Values theoretical perspective are the following:

1. For these students, values-driven concerns about the environment, developed at primary school and out of school, had continued to be influential in their early teenage years.

2. However, for these students, their earlier acquired values had now become enmeshed in a host of other value considerations, especially the limits of individual responsibility, doubts about their mandate to persuade others, and the pervasive and sometimes contrary values of early teenage culture.

3. A number of students expressed altered values connected to environmental thinking and acting than in their primary school years, although for some it seems a latency remained, perhaps to re-emerge actively later in their lives.

\section{5) Action competence}

In this part of the conversation we examined the students' and parents' views about taking action for the environment, about what motivated these actions, and perceptions of how far a student might go in taking action. The students' primary school teachers, in nominating the students for inclusion in this study, described the major activities they had been involved in at school: five students in one school had been involved in restorative native planting and designing an ecoclassroom, while three out of five students in the second school had been involved in gardening. (The remaining two students, when they were later asked directly, could not recall anything specific about environmental action at their primary school).

The student interview data, confirmed by the parents, showed evidence of the development of action competence through learning experiences at school. For example, Susan's parents were adamant that environmental experiences at primary school had influenced their daughter to act in more sustainable ways. They noted, "at one time she didn't waste water; that was one of the things that came out at school. I was cleaning my teeth one time and the tap was running, and she said 'Dad, you're wasting water'". 
However, Lucy's story is evidence of how these early commitments and actions had become entangled in the complexities of teenage life. Her parents described her now as being more interested in make-up than being outdoors, yet they noted that, "she's aware, certainly when we're on water restrictions in summer, is very aware of the importance of that. Just keeps on my back. I am not allowed to sprinkle water on the days that I'm not allowed to". Lucy had been heavily involved in a gardening club at her primary school, an experience which she claimed had been "very fun for me", and this had led to a continuing interest in gardening at home. However, she had not continued her environmental involvement at secondary school, despite opportunities being available.

Lucy's current situation was typical of the majority of these students: they frequently spoke about the conflict that they now felt between their behaviour and their thinking as regards environmental action. Brooke said, "I take long showers, I have deep baths, I leave the lights on and ... yeah, I'm not very energy- or waterwise but I probably should be". She saw this as a persisting dilemma: "After [secondary] school I want to do a bit of travelling, except the thing is the planes and the fuel and stuff. And I don't really think about that when I'm travelling, so I get really excited about travelling, but then afterwards I feel guilty". Craig's take on action was coloured less by guilt than by a kind of current suspension of resolve. His parents had noted that he had become "more of an ideas guy than an action guy", and Craig himself suggested why that might be the case: "I guess I don't feel like I can help ... because the Japanese are still whaling".

How public their action-taking could and should now be, and the inter-personal complexities involved, was a strong element in the conversations. All ten students indicated that they were still comfortable taking environmental actions in their homes, in particular participating in recycling, using low energy light bulbs, etc. (even though, as noted above, they sometimes now failed to live up to their own expectations).

Action-taking at school, in the context of peers, was more of a challenge. Brooke knew the frustrations: 'Like, they just throw out all their rubbish and they'll litter and ... I kind of, sometimes, just want to bang their heads together and say 'think about others', [but] I gave up because they just don't listen to me". Brooke is not part of the student 'Green Team' at her school, although "I support them when they do all their recycling and proposing and ... planting the trees and stuff".

Protest in the wider public arena was generally not what these students were comfortable with. A lack of confidence was a major factor. Robert's parents described him as still "quite shy about talking about things. He might disapprove of what people do but he wouldn't tell them". James, who would later describe himself as quite 'green' was very doubtful: "Protesting? Possibly ... Like people that go in tiny boats in front of massive whaling ships? I don't know if I'd really want to do that". Kerry, however, was an exception, when supported by her family. They are keenly involved in hiking in the natural environment and had recently participated in a large urban protest march against mining in a natural area. Kerry's parents said, "she came to the protest with us when we marched in 
Auckland and she was very adamant that she come because she knew about it and she wanted to come as opposed to just following us".

In overview, emergent themes pertaining to the Action Competence theoretical perspective are as follows:

1. These students were apparently keenly aware of which environmental actions were desirable. They sometimes experienced frustration at other people's lack of action, and some guilt at their own self-perceived inadequacies. They were aware that it can be a subtle and complex business, fraught with inter-personal challenges.

2. They all reported still undertaking small-scale, private actions but, as yet, generally professed a lack of confidence to risk taking more public actions.

\section{6) Environmental identity}

Both the student and parent interviews ended on a strongly personal note: How would they describe their relationship to the environment, and what terms might they (and others) use to describe that relationship?

We opened this part of the interview with students by asking them what they understood by the term 'greenie' (the colloquial term used in New Zealand for someone who shows concern for the environment). For six of the students, to be a 'greenie' had desirable connotations - it involved being admirably "passionate" (Adrian, Craig, Emily) and "environmentally friendly" (James); to be a 'greenie' means that "you value the environment and do stuff to help and protect it" (Hayley) and "you do care" (Kerry). By contrast, two interviewees considered that to be a 'greenie' involved being part of a minority whose influence was not necessarily benign - for Robert, 'greenies' were "extreme people" who "go beyond other people's limits"; and Lucy considered that 'greenies' were rather enigmatic "hippies" who were "out there". Of the remaining two interviewees (Brooke and Susan), the term 'greenie' conveyed no meaning at all. Interestingly, Kerry qualified her answer by injecting the notion of stereotypes into the conversation: 'I don't find [the term 'greenie'] offensive or anything but I do think that it is a stereotype".

When asked whether they would be willing to ascribe the term 'greenie' to themselves, the students' replies were often subtle, complex and hedged with qualifications. Robert and Kerry both embraced the term in a relaxed way: "I would be happy to be called an environmentalist, even a 'greenie', it wouldn't really bother me" (Robert) - and one (Adrian) agreed but only "if they were using it in a good way". Three others (Emily, Lucy, Susan) preferred to be described as an 'environmentally friendly person' (when the interviewer suggested it to them) rather than a 'greenie' because, as Adrian pointed out, "anything with 'friendly' in it is sort of a good way to be described". Brooke only saw herself as 'environmentally friendly' in certain contexts: "When I'm in the environment I'm an environmentally friendly person, but when I'm at home, no".

This reticence to be labelled led us to ask interviewees how they felt that their peers perceived their 'green-ness'? James and Emily were the most unequivocal. Emily said, "yeah, my friends do see me as an environmentally friendly person", and James felt his friends perceived him as 'green' "to a degree". Four others 
(Robert, Adrian, Kerry and Lucy) suggested that a perception of 'green-ness' might possibly exist, but it was not seen as their especially outstanding trait and it didn't appreciably influence their peers' behaviour. As Adrian pointed out, "Some of my friends might but some of them sort of don't see that side of me". Whatever the peer perceptions were, they were usually not seen as a matter of crucial importance to the students themselves. Robert said, "I wouldn't really mind either way, if people looked at me as someone who was environmentally friendly, someone that wasn't, because I know that I'm doing things, and I think that's all that counts, it's not whether people see me as if I'm doing stuff now". The remaining four interviewees (Craig, Susan, Hayley, Brooke) didn't know if their 'green-ness' was visible to their peers or not. Nevertheless, if their 'green-ness' was perceived by their peers, this would be no bad thing, as Hayley said, "I'm not sure. They just hopefully see that I don't harm the environment or I like to recycle and stuff".

We noted how the tentative flavour of these conversations contrasted with their previous teachers' recollections of them when they were aged nine or 10 years. Their teachers remarked on their single-minded zeal at that time and how they unself-consciously radiated that zeal to all who came in contact with them. Now, although their personal 'green-ness' may not have actually diminished, and some environmentally friendly behaviours were still evident, they appeared cautious in describing their environmental identity. They seemed generally gratified if their own desirable behaviours rubbed off on others, but they were likely to avoid behaviours that would have them labelled as environmentally evangelical in their peers' and friends' eyes.

In overview, emergent themes pertaining to the Environmental Identity theoretical perspective are as follows:

1. Students' thinking about their own environmental identity was marked by subtlety, fluidity and caution; they were generally wary about attributing environmental labels to themselves.

2. Similarly, students generally professed indifference to, or were vague about, specific environmental labels that their peers might attribute to them.

3. It does seem clear though that environmental identity is influenced by the social context in which young people find themselves, whether it be an environmentally-friendly school or home life, or their group of friends.

\section{Discussion}

This study has provided us with an intimate look into the hearts and minds of these ten 13- to 15-year-old students whom their teachers considered had enthusiastically and knowledgeably embraced environmental principles and practices in their later primary school years. We have applied six well known EEfS theoretical perspectives to explore the 'green-ness' of these students, as they transitioned from primary enviroschools that were acknowledged for doing effective EEfS, to junior secondary school years where there often appears to be an abrupt disjunction in continued EEfS learning (Williams, 2012). Rather than focus on the effectiveness of the EEfS programmes at the time, we have cast a future focus on these learners' retrospective views and development of environmental identity. 
The 13 themes which have emerged are embedded in some familiar perspectives in the literature of EEfS. However, taking the emergent themes collectively, we believe that two particular overarching findings, both often relating to aspects beyond the formal classroom setting, are worthy of discussion here.

Firstly, although school/home resonances are widely referred to as being important in general terms in individuals' development through EEfS, our conversations with students and parents in their home settings reveal how remarkably deepseated and pivotal such resonances are and can be. Thinking about their lives as a whole, it seemed to us that these 13- to 15 -year-olds were invariably unable to disentangle the part that school and home had separately played in the origin of their personal values, their behaviours (or action competence), their environmental literacy and, especially, their own environmental identity. In every case the parents were intimately acquainted with what environmental activities their children had experienced at school, and, in most cases, the enviroschools teachers were already well acquainted with the parents. There appear to have been particularly pivotal activities that had been carried out either at school and at home that were supported by the other in developing values and action competence: gardening, gully restoration, walks in the outdoors. The lack of further experiences in their secondary schooling to date seemed to have contributed to a less explicit commitment to environmentally-friendly behaviour by that time, although some students' espoused values suggested that they maintained an environmentallyfriendly outlook. Other students, though, indicated a possible regression from what Roth (1992) has described as the operational level to a more functional level of environmental literacy for the time being. These findings may suggest that each student's maturing and increasingly sophisticated powers of introspection, whilst backgrounding their environmental identity, may yet signal a latent springboard for enhanced future environmental commitment. Stapleton (2015) has noted the dynamism of environmental identity and how it can change over time, particularly in the face of reduced activity to maintain identity, and the evolving social contexts that young people find themselves in.

Secondly, our study suggests that attending to the psychological characteristics of students in their early teenage years - their capabilities, proclivities, and feelings about themselves - may have much greater leverage in cultivating EEfS than has previously been thought. The extensive review of the learning capabilities of adolescents in science education carried out from an educational psychology point of view by Anderman, Sinatra and Gray (2012) is pertinent here. These authors first characterise adolescent learners' cognitive advances compared with the situation of younger learners: adolescents are better able to consider abstract and complex relations and better able to engage in problem-solving while, at the same time, they are presented with both more specialist in-depth content and also with a much broader range of issues and diverse possibilities. But all of this provides psychological challenges to adolescents' increasing powers of adaptability. Public challenges to one's point of view can be particularly difficult for adolescents who are especially sensitive to the perceptions of their peer group members (Brown, 2004) and, cognitively, may even lead to maladaptive performance avoidance goals. Moreover, challenges to one's point of view can be emotionally difficult 
and in some cases can even be seen as a threat to one's identity (Brem, Ranney \& Schindel, 2003).

In the secondary school context, all of this plays out in both formal and informal dimensions. In classroom settings, teachers clearly need more than generalised pedagogical sensitivity to adolescents' needs; they also need specific knowledge and skills with regard to dealing with socio-scientific and environmental issues which are at the core of EEfS. In New Zealand, few secondary schools engage deeply with values exploration through EEfS, yet The New Zealand Curriculum (Ministry of Education, 2007) exhorts students to think critically about the world around them, inhabited as it is with a plethora of social and environmental issues. And concerning the informal dimension, schools need (within the bounds of student privacy) to facilitate an environment - especially for 13- and 14-year-olds experiencing peer pressure - which ensures that the gains made in previous schooling are not eroded. On these counts, the ten admirable young people we had conversations with in the present study team may not have been overly prone to peer pressure (shaped for some by the consumer-materialist culture noted by Payne, 2000) as regards their environmental beliefs and practices, and yet a concern for how others evaluate them in values and behaviour inevitably surfaced as a significant factor in our conversations.

To put it another way, these students often appeared to be struggling to rationalise an eco-centric view of the world with an ego-centric view, that is, there appeared to be a tension between how they see their relationship with the environment (Morris, 2002), and their relationship with self and peers with respect to their views of the environment and lifestyle choices (Kempton \& Holland, 2003). The secondary school years indeed appeared for these students to be a time when a rapidly expanding awareness of conflicting social priorities is being negotiated, and caring for the environment necessarily jostles with the task of establishing an identity of self (Blatt, 2014; Sauve, 2010) which is secure and sustainable. We agree with Stapleton (2005) that environmental action and recognition appear to be important elements in developing and retaining a socially-influenced environmental identity, and also that aspects of social identity formation (Wenger, 1998) appeared to be in tension with environmental identity formation for some of these teenagers. The negotiation of this tension through these teenage years may reflect how significant life experiences and shifting value sets may impact on the resilience of identity through the type of salience, empowerment and activism that Kempton and Holland (2003) have described in their work with adults. The findings of this study seen through multiple perspectives have also indicated that the natural world (and experiences within it) are important in identity formation.

\section{Finally, the Future}

Given that EEfS is inevitably and appropriately associated with the notion of lifelong learning, where might the trajectories of these ten young people's lives be heading? Where might their environmental learning have taken them in, for example, five years' time? Near the end of our conversations, we asked them if they were interested in pursuing an environment-related career after finishing school. Replies covered a wide spectrum. 
No-one aspired to be an environmentalist as such. James entertained the idea in general terms, saying "I'd definitely consider that. I'd probably enjoy it", but had no specific plans. On the other hand, for Robert and Adrian, working on the ecoclassroom had had a deeply significant impact: it motivated Robert to talk seriously and decisively to a friend's architect uncle who is interested in sustainability; and Adrian, who had worked on the wastewater storage tank for the classroom, was similarly thinking deeply about architecture.

Four students were thinking about career choices in the health area but were, however, thinking carefully about the environmental connotations. Kerry indicated that she wanted "to be a vet when I'm older, focussing on Department of Conservation animals, I'm really interested in that sort of area". Brooke was considering nutrition as a career with an environmental slant, saying "we need to eat healthy and organic now. They've discovered more allergies and the severity of allergies, so I can help people with coeliac disease and such". Hayley had her sights set on becoming a doctor but showed that she was thinking deeply about the flow of energy and materials through medical systems when she noted that "the syringes and stuff that can only be used once and you just have to chuck them out and they're not biodegradable or something". The remaining students appeared to have no intention of a career involving the environment specifically, which doesn't discount the possibility for non-vocational environmentalism, as many of those in the environmental movement today are volunteers.

To follow these young people in their life trajectories through longitudinal research would not only be fascinating, it would provide great insights into how environmental literacy and identity develops over time. Such a project (the 'Dunedin Study') in the health sector in New Zealand has delivered world-leading research that is shaping the way we see treatment of health issues throughout the early part of life (Dunedin Multidisciplinary Health and Development Research Unit, 2016). The richness of the data in this study illustrates the potential for helping us to understand the influences on environmental literacy and identity and how we could tailor our educative efforts, both in school and home, towards a more sustainable future.

\section{Acknowledgements}

We are grateful to our ten interviewees and their parents for their comprehensive and forthright conversations with us. We also express our gratitude to the staff of the two New Zealand enviroschools involved in this study, and in particular we thank our three principal teacher colleagues and co-researchers - Michelle White, Linda Watson and Marianne Robertson - for their wisdom and their resolute encouragement.

\section{References}

Aguirre-Bielschowsky, I., Freeman, C., \& Vass, E. (2012). Influences on children's environmental cognition: A comparative analysis of New Zealand and Mexico. Environmental Education Research, 18(1), 91-115.

Almers, A. (2013). Pathways to action competence for sustainability: Six themes. The Journal of Environmental Education, 44(2), 116-127.

Alvesson, M. \& Sandberg, J. (2013). Constructing research questions: Doing interesting research. Los Angeles: Sage. 
Anderman E., Sinatra, G., \& Gray, D. (2012). The challenge of teaching and learning about science in the twenty-first century: Exploring the abilities and constraints of adolescent learners. Studies in Science Education, 48(1), 89-117.

Arnold, H. E., Cohen, F. G., \& Warner, A. (2009). Youth and environmental action: Perspectives of young environmental leaders on their formative influences. The Journal of Environmental Education, 40 (3), 27-36.

Barker, M. (2008). The New Zealand Curriculum and preservice teacher education: Public document, private perceptions. Curriculum Matters, 4, 7-19.

Barker, M. (2012, January). "What made you green?": Some older Kiwis' reflections. Paper presented at the New Zealand Association for Environmental Education biennial conference, Hamilton, New Zealand.

Bennetts, C. (2003). The impact of transformational learning on individuals, families and communities. International Journal of Lifelong Education, $22 \quad$ (5), 457-480.

Blatt, E. (2014). Uncovering students' environmental identity: An exploration of activities in an environmental science course. The Journal of Environmental Education, 45(3), 194-216.

Brem, S. K., Ranney, M. \& Schindel, J. (2003). Perceived consequences of evolution: College students perceive negative personal and social impact of evolutionary theory. Science Education, 87(2), 181-206.

Brown, B. (2004). Adolescents' relationships with peers. In R. Lerner \& L. Steinberg (Eds.), Handbook of adolescent psychology (pp. 363-394). New York: Wiley.

Callenbach, E. (2005). Values. In M. K. Stone and Z. Barlow (Eds.) Ecological literacy: Educating our children for a sustainable world (pp. 45-48). San Francisco: Sierra Club Books.

Chawla, L. (1999). Life paths into effective environmental action. Journal of Environmental Education, 31(1), 15-26.

Chawla, L., \& Cushing, D. (2007). Education for strategic environmental behaviour. Environmental Education Research, 13(4), 437-452.

Dunedin Multidisciplinary Health and Development Research Unit (2016). Retrieved from http://dunedinstudy.otago.ac.nz/.

Eames, C., \& Barker, M. (2011). Understanding student learning in Environmental education in Aotearoa New Zealand. Australian Journal of Environmental Education, 27 (1), 186-191.

Eames, C., Barker, M., Wilson-Hill, F. \& Law, B. (2010). Investigating the relationship between whole-school approaches to education for sustainability and student learning. A summary. Wellington: New Zealand. New Zealand Council for Educational Research.

Enviroschools. (2016). Enviroschools programme. 2016, from http://www.enviroschools.org.nz/

Fielding, K. S., \& Head, B. W. (2012). Determinants of young Australians' environmental actions: The role of responsibility attributions, locus ofcontrol, knowledge and attitudes. Environmental Education Research, 18(2), 171-186.

Fromm, E. (1976). To have or to be? New York: Harper \& Row.

Hart, P. (2003). Teachers' thinking in environmental education. New York: Peter Lang Publishing.

Hollweg, K., Taylor, J., Bybee, R., Marcinkowski, T., McBeth, W., \& Zoido, P. (2011). Developing a framework for assessing environmental literacy. Washington, DC: North American Association for Environmental Education.

Hudson, F. M. (1999). The adult years: Mastering the art of self-renewal. San Francisco: Jossey-Bass.

Hutchison, D. (1998). Growing Up Green: Education for Ecological Renewal. New York: Teachers' College Press.

Jensen, B. (2002). Knowledge, action and pro-environmental behaviour. Environmental Education Research, 8(3), 325-334. 
Jensen, B. B. \& Schnack, K. (1997). The action competence approach to environmental education. Environmental Education Research, 3(2), 163-178.

Kasapoğlu, A., \& Turan, F. (2008). Attitude-behaviour relationship in environmental education: A case study from Turkey. International Journal of Environmental Studies, 65(2), 219-231.

Kempton, W., \& Holland, D. C. (2003). Identity and sustained environmental practice. In S. C. S. Opotow (Ed.), Identity and the natural environment: The psychological significance of nature (pp. 317-341). Cambridge,MA: MIT Press.

Keown, P. (2000). Values education in New Zealand: Some implications of recent research and development. Research seminar presented at the Institute of Education, London.

Keown, P. (2002). Aotearoa - New Zealand. In J. Fien, D. Yencken \& H. Sykes (Eds.) Young People and the Environment: An Asia-Pacific Perspective (pp.115-125). Dordrecht: Springer.

Lawley, J. (2002). Values education in schools: An investigation of values education in schools and education support organizations in Canada and U.S.A. Report prepared for the Winston Churchill Memorial Trust.

Manawatu Standard (2013). A greenie and proud of it. Retrieved from http://www.stuff.co.nz/manawatu-standard/opinion/9118923/A-greenie-andproud-of-it

Mezirow, J. (Ed.). (2000). Learning as transformation: Critical perspectives on a theory in progress. San Francisco, CA: Jossey-Bass.

Ministry of Education (2007). The New Zealand Curriculum. Wellington, New Zealand: Learning Media.

Mogensen, F., \& Schnack, K. (2010). The action competence approach and the 'new'theoretical perspectives of education for sustainable development, competence and quality criteria. Environmental Education Research, 16(1), 59-74.

Morris, M. (2002). Ecological consciousness and curriculum. Journal of Curriculum Studies, 34(5), 571-587.

Naess, A. (1989). Ecology, Community and Lifestyle: Outline of an Ecosophy, translated by D. Rothenberg. Cambridge: Cambridge University Press.

Ohman, J. (2008). Introduction. In J. Ohman (Ed.), Values and democracy in education for sustainable development: Contributions from Swedish research (pp. 11-16). Malmo: Liber.

Orr, D. (1992). Ecological literacy: Education and the transition to a Postmodern World. Albany, NY: SUNY Press.

Payne, P. (2000). Identity and environmental education. Environmental Education Research, 7(1), 67-88.

Prabawa-Sear, K., \& Baudains, C. (2011). Asking the participants: Students' views on their environmental attitudes, behaviours, motivators and barriers. Australian Journal of Environmental Education, 27(2), 219-220.

Roth, Charles E. (1992). Environmental literacy: Its roots, evolution, and directions in the 1990s. Columbus, OH: ERIC/CSMEE.

Sauve, L. (2010). Being here togther. In McKenzie,, M., Hart, P., Bai, H. and Jickling, B. (Eds). Fields of green: Restorying culture, environment and education, pp. 325337. Cresskill, NJ: Hampton.

Shepard, P. (1982). Nature and madness. London: University of Georgia Press.

Stapleton, S.R. (2015). Environmental identity development through social interactions, action, and recognition. Journal of Environmental Education, 46(2), 94-113,

Sterling, S. (2001). Sustainable education: Revisioning learning and change. Bristol: The Schumacher Society.

Stets, J. \& Biga, C. (2003). Bringing identity theory into environmental sociology. Sociological Theory, 21(4), 389-423.

Tanner, T. (1980). Significant life experiences. The Journal of Environmental Education, 11(4), 20-24. 
Thomashow, M. (1995). Ecological identity: Becoming a Reflective Environmentalist. Cambridge MA: MIT Press.

Van Matre, S. (1990). Earth Education: A New Beginning. Greenville, WV: Institute for Earth Education.

Wake, S. J., Eames, C. (2013). Developing an "ecology of learning" within a school sustainability co-design project with children in New Zealand. Local Environment: The International Journal of Justice and Sustainability. 18 (3), 305-322.

Wals, A.E.J, Geerling-Eijff, F., Hubeek, F., van der Kroon, S. \& Vader, J. (2008). All mixed up? Instrumental and emancipatory learning toward a more sustainable world: Considerations for EE policymakers. Applied Environmental Education and Communication, 7, 55-65.

Wenger, E. (1998). Communities of practice: Learning as a social system. Systems Thinker, 9(5), 1-10.

Wickenberg, P., \& Almers, E. (2008). Breaking and making norms: Young people's stories of consumption actions for sustainable development. In J. Ohman (Ed.), Values and democracy in education for sustainable development: Contributions from Swedish research (pp. 165-186). Malmo: Liber.

Williams, P. (2012). Educating for sustainability in New Zealand: Success through Enviroschools. In M. Robertson (Ed.), Schooling for sustainable development: A focus on Australia, New Zealand and the Oceanic Region (pp. 33-48). Dordecht, Germany: Springer.

Wilson-Hill, F. (2003). Children's participation in environmental education: an analysis of Enviroschools - a whole school approach to environmental education. Unpublished Masters thesis, Griffith University, November 2003. 